특집논문 (Special Paper) 방송공학회논문지 제19권 제1호, 2014년 1월 (JBE Vol. 19, No. 1, January 2014) http://dx.doi.org/10.5909/JBE.2014.19.1.14

ISSN 2287-9137 (Online) ISSN 1226-7953 (Print)

$$
\begin{gathered}
\text { 초고속 클라우드 비디오 서비스 실현을 위한 } \mathrm{SDN} \text { 기반의 다중 무선 } \\
\text { 접속 기술 제어에 관한 연구 } \\
\text { 김 동 햐라, 이 성 원 }
\end{gathered}
$$

\title{
A Study of Development for High-speed Cloud Video Service using SDN based Multi Radio Access Technology Control Methods
}

\author{
Dongha Kim ${ }^{\mathrm{a})}$ and Sungwon Lee ${ }^{\mathrm{a})^{\ddagger}}$
}

요 약

본 논문은 최근 이동통신 네트워크에서 폭발적으로 증가하고 있는 비디오 트래픽이 야기한 문제와 요구사항의 해결책으로써, $\mathrm{SDN}$ (Software Defined Network)을 기반으로 하는 다중 무선 접속 기술(Multiple Radio Access Technology)의 제어 기법을 제안하고 그 성능을 자체 구축한 테스트베드를 통하여 평가한다. 이를 위하여, 먼저 사업자 입장에서 3rd-party의 비디오 트래픽을 사업자망으로 부터 우회(off-loading)시키는 방안의 필요성과, 사용자에게 저비용으로 고속의 대용량 비디오 콘텐츠 서비스를 제공하는 방안에 대하 여 논의한다. 또한 성능평가를 위한 테스트베드는 OpenStack 클라우드 및 SDN 기반으로 구축 하였다. 이를 통해, OpenFlow와 Open vSwitch를 이용하여 2 개의 $2.4 \mathrm{GHz}$ 무선 랜 링크와 3 개의 $5 \mathrm{GHz}$ 무선 랜 링크가 동시에 하나의 서비스를 지원하도록 함으로서 820 $\mathrm{Mbps}$ 급의 초고속 클라우드 비디오 서비스를 위한 전송 속도를 실현하였다.

\section{Abstract}

This paper proposed controlling methods for SDN(Software Defined Network) based multiple radio access technology as the solutions of following two issues which were mainly occurred by explosive increasing of video traffic. The first one is a requirement for traffic off-loading caused by 3rd-party video service providers from the mobile network operator's viewpoint. The other one is a provision of high-speed video contents transmission services with low price. Furthermore, the performance evaluation was also conducted on the real test-bed which is composed of OpenStack cloud and SDN technology such as OpenFlow and Open vSwitch. A virtual machine running on the OpenStack provide a video service and the terminal which is able to use multiple radio access technology supports two 2.4GHz WLANs(Wireless Local Area Network) and three 5GHz WLANs, concurrently. Finally, we can get $820 \mathrm{Mbps}$ of the maximum transmission speed by using that five WLAN links for the single service at the same time.

Keyword : SDN, cloud video service, traffic offloading, multiple-RAT, heterogeneous network

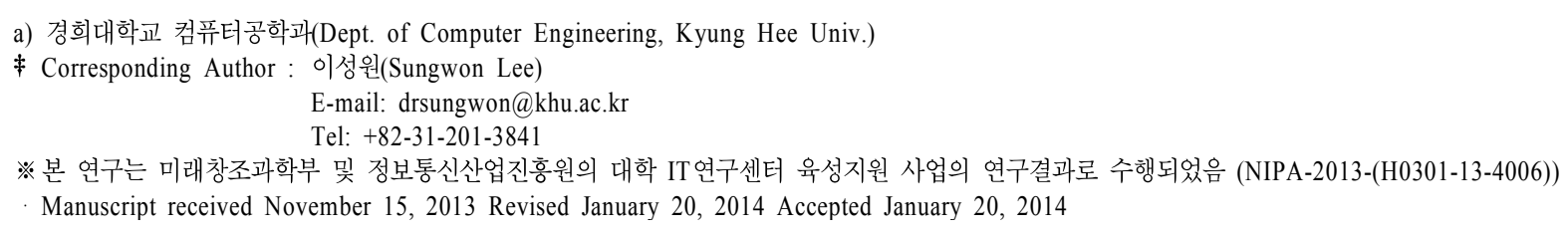




\section{I. 서 론}

비디오 서비스는 현재의 이동통신 네트워크에서 가장 중 요한 트래픽이다. 실제 비디오 서비스로 인해 발생하는 트 래픽은 이미 세계 인터넷 트래픽의 $50 \%$ 를 넘어섰으며, 2017년에는 전 세계 네트워크 트래픽의 약 $70 \%$ 를 차지할 것으로 예상되고 있다 ${ }^{[1-2]}$. 이러한 이동통신 네트워크에서 의 폭증적인 비디오 트래픽의 증가는 다음의 두 가지 문제 를 야기하게 되었다. 첫째는 사업자의 콘텐츠가 아닌 3rd-party 서비스 제공업자의 비디오 트래픽을 이동통신 네 트워크에서 우회(off-loading)시키는 방안에 대한 필요성의 대두이고, 둘째는 사용자와 콘텐츠 제공업자 입장에서 보 다 저렴한 무선 기술을 통해 고속으로 대용량, 고화질의 비 디오 콘텐츠를 제공하고, 서비스를 제공받고자 하는 요구 의 증대이다.

첫 번째와 두 번째 방안에 대한 현실적인 해답은 HetNet (Heterogeneous Network)으로 대두되고 있다 ${ }^{[3]}$. 즉, 사용자 입장에서 비디오 서비스를 제공받기 위하여 보다 저렴하지 만 고속의 전송 속도를 지원하는 무선 랜(WLAN: Wireless Local Area Network) 기술을 이동통신 네트워크 기술과 함 께 사용하는 것이다. 과거에도 이와 관련한 연구가 일부 있 었지만 ${ }^{[4-6]}$, 대부분 $\mathrm{ABC}$ (Always-Best-Connected)의 개념 으로서, 특정 핸드오버 상황 혹은 현재 위치한 곳에서 가장 최적의 무선 기술을 선택한다는 의미였다. 즉, 주어진 상황 에서 최적의 단일 무선 기술을 선택한다는 접근이다. 하지 만, 무선 단말이 지원하는 무선 접속 기술의 종류가 점차 많아질 것이므로 앞으로의 연구는 복수의 무선 기술을 하 나의 서비스를 위하여 동시에 사용하는 측면으로 보다 발 전할 것이다.

본 논문에서는 이러한 관점에서 초고속 비디오 서비스를 실현하기 위하여 SDN(Software Define Network)을 기반으 로 하는 다중 무선 접속 기술을 실현하고, 이에 대한 성능평 가를 실제 테스트베드를 통하여 실시한다. 즉, $\mathrm{SDN}$ 의 OpenFlow $^{[7]}$ 를 소프트웨어 스위치인 OVS(Open vSwitch) ${ }^{[8]}$ 의 제어 목적으로 활용하여, 다중 무선 접속 기술을 동시에 사용한 초고속 비디오 트래픽을 동적으로 제어할 수 있는 방안에 대하여 논의한다. 이를 위하여 OpenStack 클라우드
컴퓨팅 플랫폼 ${ }^{[9]}$ 이 고려되었으며, OpenStack 플랫폼 위에 서 제공되는 비디오 서비스를 단말이 가진 다수의 무선 접 속 기술을 사용하여 고속으로 제공받는 시나리오로 실제 테스트베드를 구축하고 성능을 측정하였다.

본 논문은 다음과 같은 구성으로 되어 있다. 제 팡에서 는 제안하고자 하는 $\mathrm{SDN}$ 기반의 다중 무선 접속 기술 제어 기법과 관련된 선행 연구를 소개하고 설명한다. 제 피장에 서는 본 논문에서 제안하는 SDN 기반의 다중 무선 기술 제어 기법에 대하여 설명하며, 제 IV장에서는 실제 테스트 베드를 통하여 수행한 성능평가의 결과를 소개하고 분석한 다. 마지막으로 제 $\mathrm{V}$ 장에서 본 논문에 대한 결론을 맺는다.

\section{II. 관련 연구}

본 논문과 관련된 기존의 연구는 복수의 무선 기술을 사 용하여 통신을 수행하는 HetNet과 OpenFlow를 기반으로 하는 $\mathrm{SDN}$ 기술이 존재한다. 본 장에서는 위의 관련 연구에 대해 설명하고, 본 논문에서 제안하고자 하는 방안과 어떠 한 차이가 있는지 논의한다.

\section{Heterogeneous Network}

본 논문에서는 초고속 클라우드 비디오 서비스의 실현을 위해 단말이 사용 가능한 다수의 이종 무선 접속 기술을 $\mathrm{SDN}$ 기반 기술로 제어하는 방안을 제안하고자 한다. 이는 최근 HetNet으로 대두되고 있는 연구 분야와 그 본질이 같 다고 할 수 있다. 그러나 기존 HetNet 관련 연구는 대개 $\mathrm{ABC}$ 의 개념이었다. 예를 들어, $\mathrm{M} 2 \mathrm{M}$ (Machine-to-Machine) 통신 관점에서 IEEE 802.11 무선 랜 기술과 3GPP EPC (Evolved Packet Core) Network 이동통신 기술 사이의 효 율적인 핸드오버(vertical hand-over)와 관련된 연구 ${ }^{[5]}$ 를 에 너지 효율성에 중점을 두고 진행 하거나, 단말이 이종 네트 워크 간 이동 시 컨텍스트(context)와 위치를 기반으로 효과 적인 핸드오버를 수행하는 것과 관련된 연구 ${ }^{[6]}$ 가 주된 형태 이다. 즉, 단말이 사용할 수 있는 다수의 무선 접속 기술 중 최적의 것을 매 순간 하나씩 선택하는 $\mathrm{ABC}$ 의 개념으로 
연구들이 진행되어 왔다.

그러나, 본 논문의 선행 연구 ${ }^{[10]}$ 에서 제안한 바와 같이 $\mathrm{SDN}$ 을 기반으로 다수의 무선 접속 기술을 동시에 활용하 여 성능을 증대시키는 방향의 연구는 진행된 바가 없으며 단지 멀티 호밍 문제를 해결하기 위해 프로토콜 계층을 수 정 하는 방안으로 진행된 연구 ${ }^{[1-12]}$ 가 있을 뿐이다.

\section{OpenFlow 및 Open vSwitch}

OpenFlow는 당시 스탠포드 대학의 박사과정이었던 Martin Casado가, 네트워크 보안 관점에서 중앙 집중식의 컨트롤러가 플로우를 제어하는 네트워크 아키텍처 개념으 로 2007년 발표한 이단(Ethane)이 ${ }^{[13]}$ 그 시초이다. 이후 대 학 주도로 OpenFlow 프로젝트가 수행되어왔고, 2011년 3 월에 OpenFlow 기술의 체계적 발전 및 상용화를 촉진시키 기 위해 표준화 단체인 ONF(Open Networking Foundation)이 설립되었다. 이후 ONF는 OpenFlow를 소프트웨어 중심의 네트워킹 기술을 개발하기 위한 목표로써의 SDN 개념에 확장 및 통합하여 표준화를 추진하고 있다 ${ }^{[14]}$.

$\mathrm{ONF}$ 에서 정의하는 $\mathrm{SDN}$, 즉 소프트웨어 중심의 네트워 킹 기술의 구조는 기존 컴퓨터 시스템과 매우 유사하다. 즉, 최상단의 응용 계층은 컴퓨터 시스템의 그것과 같으므 로 네트워크 사용자는 컴퓨터 시스템의 OS(Operating System)에 해당하는 하단의 제어 계층에 대한 API만 준수 하면 실제 네트워크를 이루는 하드웨어의 종류와 무관하게 응용 프로그램을 사용할 수 있다. 여기서 제어 계층은
$\mathrm{NOX}^{[15]}$ 또는 Floodlight ${ }^{[16]}$ 와 같은 논리적으로 중앙 집중화 된 네트워크 제어 플랫폼을 의미하며 실제로 이들은 'Network OS'라고 불리기도 한다. 또한, 논리적인 중앙 집 중화의 의미는 물리적으로는 두 개 이상의 컨트롤러가 존 재할 수 있음을 의미한다 ${ }^{[17]}$. 이때, 제어 계층과 최하단의 물리 계층 사이의 인터페이스가 바로 OpenFlow와 같은 프 로토콜이며, $\mathrm{ONF}$ 는 이와 같은 추상화 개념의 도입으로 네 트워킹 기술의 중심이 하드웨어에서 소프트웨어로 이동할 수 있음을 강조한다.

한편, OpenFlow 스위치는 x86 아키텍처 기반의 PC, OpenFlow가 구현된 상용 스위치 박스 또는 본 연구에서 주로 사용한 OVS와 같은 가상 소프트웨어 스위치까지 다 양한 형태가 될 수 있다. OpenFlow 스위치는 자신을 거쳐 흐르는 패킷(프레임)들의 헤더 정보를 조합하여 개별 플로 우로 제어할 수 있다. 즉, 출발지 또는 목적지 MAC 주소 또는 IP 주소, 혹은 전송 계층 포트 번호 등을 기준으로 패 킷들을 개별 플로우로 구분하여 이들에 대한 제어를 수행 할 수 있다. 그림 1은 1.1 버전 기준의 OpenFlow가 다루는 플로우 테이블 및 헤더 정보이다. OpenFlow 스위치는 스위 치로 들어온 패킷의 헤더와 그림 1 의 매치 필드에 명시된 정보를 비교하여 해당하는 처리(Action)을 수행하는 기본 체제로 패킷을 처리하는 방법으로 플로우를 제어하게 된다. 이때 가능한 패킷의 처리 방법은 스위치의 특정 포트로 패 킷을 포워딩 하거나, 패킷을 버리거나(Drop), 컨트롤러에게 전달하는 것부터, 출발지 $\mathrm{MAC}$ 주소, IP 주소 또는 전송 계 층 포트 번호를 수정하거나 하는 등의 패킷의 특정 필드를

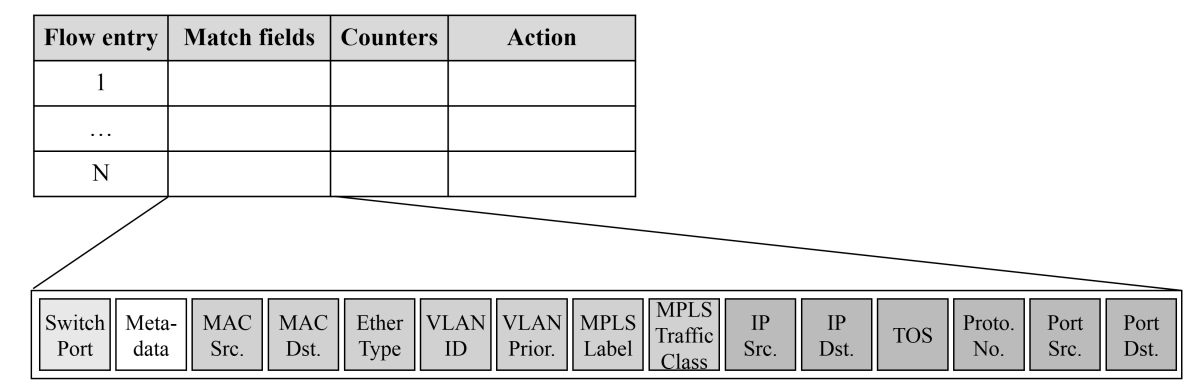

그림 1. OpenFlow 버전 1.1의 플로우 테이블 및 헤더 정보

Fig. 1. The flow table and header information of OpenFlow version 1.1 
수정 하는 것 까지 다양하다.

한편, Open vSwitch는 소프트웨어 스위치로, Dom0 또는 Xen과 같은 하이퍼바이저나 관리 도메인(Management domain) 내부에 존재하며 가상머신과 물리적인 네트워크 인 터페이스 사이의 연결성을 제공한다 ${ }^{[8]}$. 또한, OVS는 가상 스위치에 대한 중앙 집중식의 관리를 위한 외부 인터페이 스를 지원하고 1.4 버전 기준으로 OpenFlow 1.1 버전이 구 현되어 있으므로 OpenFlow 스위치로 동작할 수 있다.

\section{III. 제안하는 SDN 기술 기반의 다중 무선 접속 기술 제어 기법}

본 장에서는 제안하는 기법이 적용될 수 있는 실제 사용 시나리오를 알아보고, 그로 인해 얻을 수 있는 이점에 대하 여 논의한다. 또한, 액세스 네트워크에 위치한 OpenFlow 스위치가 단말들에게 초고속 클라우드 비디오 서비스를 제 공하기 위하여 네트워크와 단말의 Open vSwitch를 제어하 는 기법과 그를 위한 제어 모듈에 대하여 설명한다.

\section{1. 제안하는 기법의 활용 시나리오}

제안하는 기법을 통해 실제 이동통신 네트워크 사업자와
서비스 사업자 또는 사용자 입장에서 어떠한 이점을 얻을 수 있는지 알아 볼 필요가 있다. 그림 2는 제안하는 $\mathrm{SDN}$ 기반의 다중 무선 접속 기술 제어 기법을 사용하여, 비디오 서비스를 포함한 멀티미디어 서비스를 클라우드 서비스로 제공받는 개념과 대표 시나리오를 도식화 한 것이다. 그림 2에서 좌측의 사진, 비디오, 음악, IPTV 등으로 대표되는 멀티미디어 서비스는 클라우드 인프라스트럭처 위에서 사 용자에게 제공되며, 클라우드의 앞단에는 필요에 따라 OpenFlow 스위치가 존재한다. 그림 2의 우측에 위치한 사 용자는 다중 무선 접속 기술을 사용할 수 있는 단말을 사용 하고 있는 것으로 가정하며 그림에는 사용할 수 있는 무선 접속 기술로 다수의 무선 랜과 4 세대 이동통신이 도식화 되어 있다. 또한, 사용자의 단말에도 OVS가 설치되어 있고 네트워크에 존재하는 다른 OpenFlow 스위치와 제어 목적 의 통신이 가능하다.

그림 2의 얇은 점선 및 (1)로 표시된 시나리오는 트래픽 의 우회(off-loading) 시나리오이다. 이동통신 네트워크 사 업자의 입장에서, 다수의 사용자가 멀티미디어 서버로부터 대용량의 비디오 서비스를 제공받는 경우 네트워크 부하가 발생할 수 있다. 이때 사용자가 무선 랜 $\mathrm{AP}$ 의 커버리지 안 에 존재하여 해당 무선 자원을 사용할 수 있다면 네트워크 사업자로서는 3rd-party 사업자의 비디오 트래픽을 자신들 의 네트워크가 아닌 다른 네트워크로 우회시킬 수 있다는

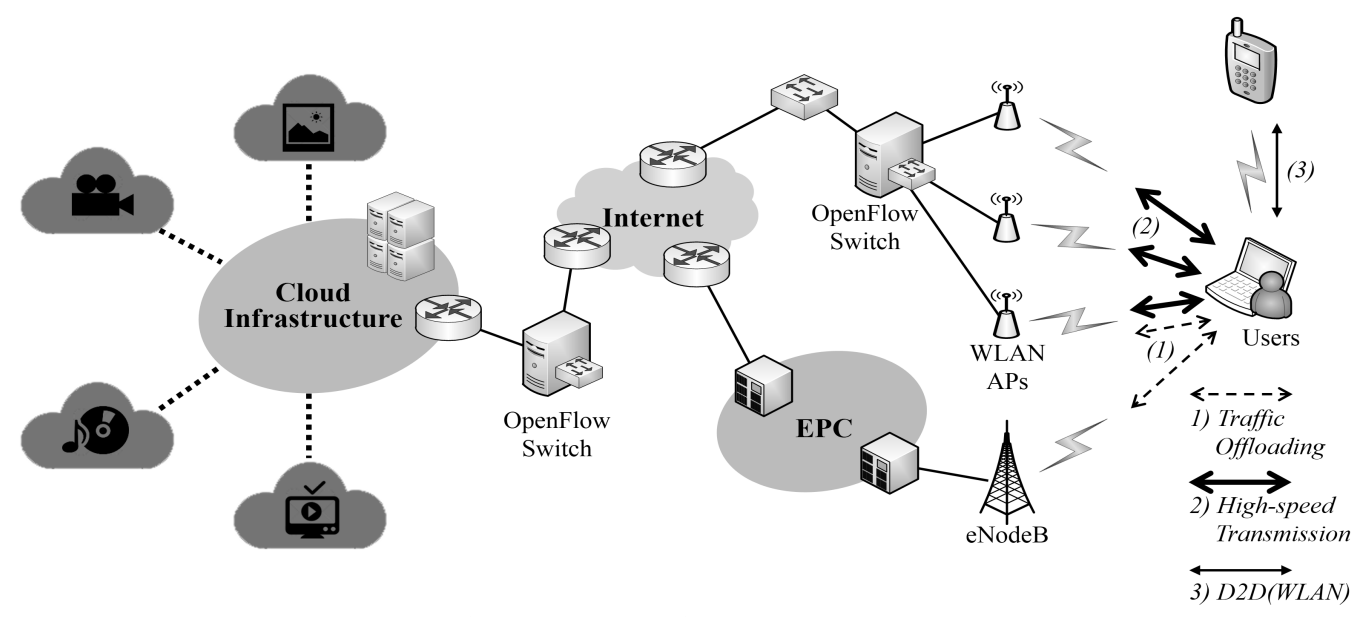

그림 2. OpenFlow와 Open vSwitch를 사용한 디중 무선 접속 기술 제어의 개념과 주요 활용 시나리오

Fig. 2. The main concept of controlling method for multiple radio access technology using OpenFlow and Open vSwitch 
장점이 있다. 사용자 입장에서도, 네트워크 사용료가 상대 적으로 저렴하거나 무료인 무선 랜을 통하여 조금 더 빠른 속도로 비디오 서비스를 제공받을 수 있으므로 이점을 갖 는다. 또한, 이 경우 무선 랜은 상대적으로 커버리지가 좁아 지속적인 연결성이 보장되기 힘든 경우가 발생할 수 있으 므로 비디오 서비스의 제어 트래픽은 여전히 이동통신 네 트워크로 통과시켜 장애 복구(fail-over) 까지 대비할 수 있 다.

그림 2의 굵은 실선 및 (2)로 표시된 것은 다수의 무선 랜 인터페이스를 동시에 활용하여 고속의 전송 속도를 확 보하는 시나리오이다. 이때 사용자의 단말은 다수의 무선 랜 인터페이스를 가지고 있고, 주변에는 접속할 수 있는 무 선 랜 $\mathrm{AP}$ 의 개수가 충분하다고 가정한다. 이러한 경우 사 용자 입장에서 실제로 활용 가능한 시나리오는 크게 두 가 지로 분류될 수 있다. 첫 번째는 사용자의 단말이 동시에 여러 목적지 서버와 트래픽을 주고받는 경우이다. 이러한 경우 각각의 트래픽을 개별 플로우로 구분하고 플로우 마 다 전용의 무선 랜 링크를 통해 트래픽을 주고받을 수 있도 록 제어할 수 있다. 이때 사용자의 단말과 액세스 네트워크 뒷 단에 위치한 OVS는 단말과 목적지 서버의 IP 주소를
그림 1 의 플로우 테이블에 명시된 매치 필드로 적용하여 플로우를 제어할 수 있다. 두 번째는 사용자의 단말이 단일 목적지 서버와 트래픽을 주고받고 있으나, 단말과 서버가 동시에 여러 개의 응용 프로그램을 사용하여 각각 다른 전 송 계층 포트 번호로 트래픽을 주고 받는 경우이다. 이 경우 에는 앞서 설명한 첫 번째 경우와 유사하나, 플로우 테이블 에서 포트 번호로 플로우를 구분하고 제어하게 된다.

마지막으로 그림 2의 얇은 실선 및 (3)으로 표시된 것은 3GPP(3rd Generation Partnership Project)에서 고려하는 $\mathrm{D} 2 \mathrm{D}$ (Device-to-Device) 모델 ${ }^{[18]}$ 을 고려하여 단말간의 무선 랜 기술을 통한 직접 데이터 송수신이 가능하되, 단말간의 식별 및 연결설정은 이동통신 기술을 활용하는 시나리오이 다. 이는 일부 $\mathrm{CDN}$ (Content Delivery Network) 개념과도 유사한 것으로, 네트워크의 부하를 줄이고 상대적으로 높 은 전송 속도를 확보할 수 있는 장점이 있다.

앞서 논의한 바와 같이, 기존 TCP/IP 및 라우팅 프로토콜 에 종속적인 네트워크에서는 구현하기 힘든 플로우 제어가 제안하는 방안을 통해 가능함을 확인할 수 있었다. 다음 절 에서는, 제안한 $\mathrm{SDN}$ 기반의 다중 무선 접속 기술 제어 기 법이 적용되어, 초고속 클라우드 비디오 서비스를 제공하

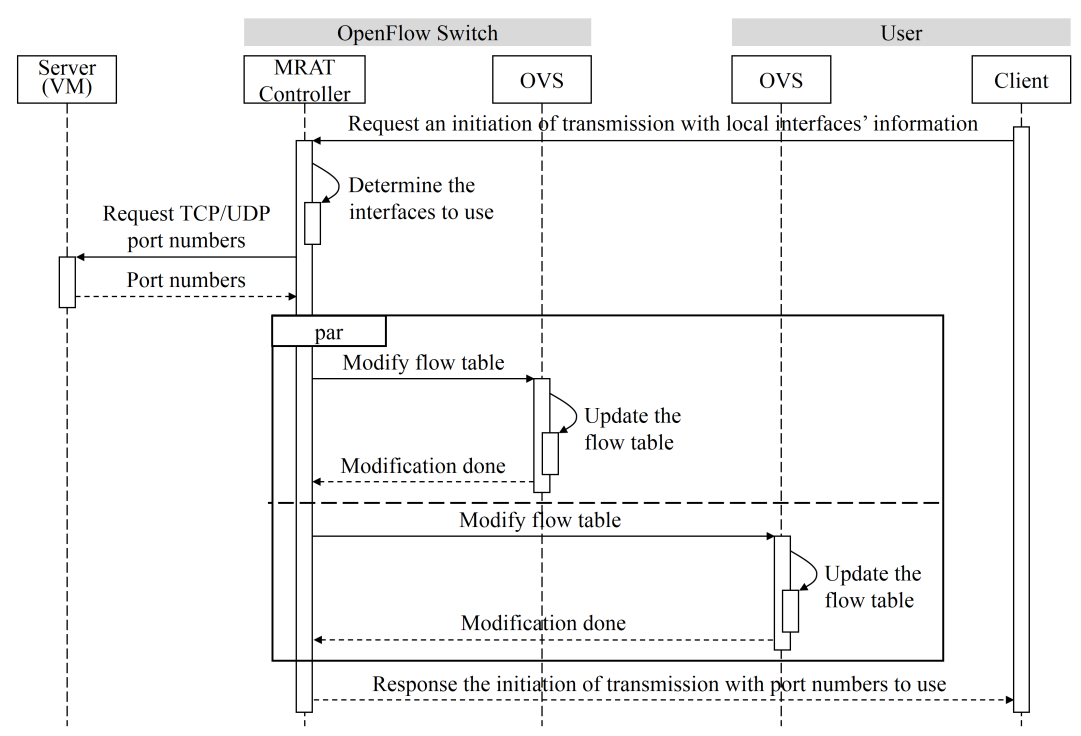

그림 3. 제안하는 다중 무선 접속 기술 제어 모듈의 클라이언트 전송 개시 요청 처리

Fig. 3. Handling the transmission initiation request of client conducted by MRAT Controller 
기 위한 제어 모듈에 관해 서술한다.

\section{2. 초고속 클라우드 비디오 서비스 제어 기술}

제안하는 $\mathrm{SDN}$ 기반의 다중 무선 접속 기술 제어 기법을 활용하여 사용자에게 초고속 클라우드 비디오 서비스를 제 공하기 위해서는 별도의 제어 모듈이 필수적이다. 기존의 파일 전송 및 동영상 스트리밍 애플리케이션의 경우 일반 적으로 단일 전송 계층 포트를 사용하여 소켓 통신을 수행 하기 때문이다. 제안한 다중 무선 접속 기술 제어 기법은 기본적으로 단일 서버와 단일 클라이언트의 트래픽을 전송 계층 포트 번호로 구분한다. 따라서 사용 가능한 무선 접속 기술의 개수와 동일한 전송 계층 포트 번호를 동시에 이용 한 소켓 통신을 지원하는 추가적인 제어 모듈이 필요하다.

그림 3은 제안하는 제어 모듈(Multi-RAT Controller)이 클라이언트가 최초 파일 전송(서비스 요청)의 개시를 요청

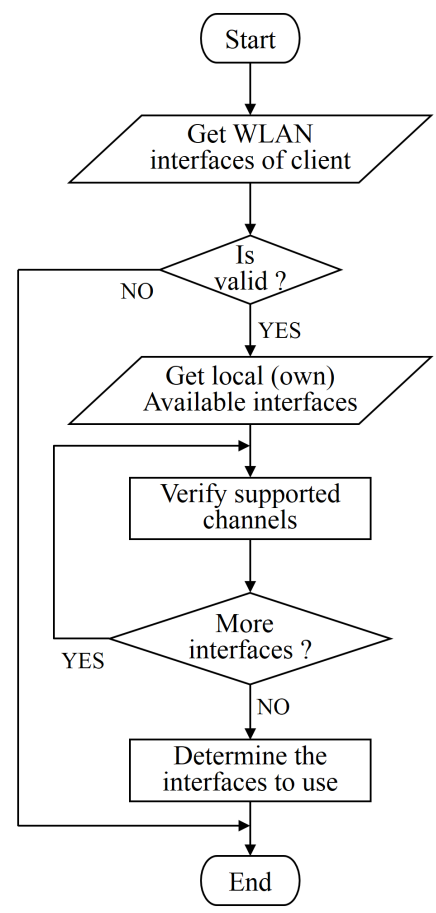

그림 4. 제안하는 디중 무선 접속 기술 제어 모듈의 네트워크 인터페이스 탐색 절차

Fig. 4. Determining process of network interfaces for notifying to the client
하는 경우의 처리 동작을 나타내는 시퀸스 다이어그램이다. 먼저, 클라이언트는 비디오 서버에 서비스를 요청하기 전 에, 이 사실을 액세스 네트워크에 존재하는 제어 모듈에 알 릴 필요가 있다. 이때 클라이언트는 단말이 지원하는 네트 워크 인터페이스의 개수와 종류에 대한 정보를 포함하여야 한다. 본 논문에서는 단말의 무선 접속 기술로 무선 랜 인터 페이스를 가정하므로, 각 무선 랜 인터페이스가 지원하는 주파수 대역 및 지원 채널 정보도 포함되어 있어야 한다. 해당 정보를 수신한 OpenFlow 스위치 내부의 제어 모듈은, $\mathrm{AP}$ 모드로 동작하고 있는 OpenFlow 스위치의 무선 랜 인 터페이스 중에서 요청한 단말이 접속할 수 있는 인터페이 스를 결정한다. 이 과정은 그림 4 에 나타나 있다. 제어 모듈 은 OpenFlow 스위치의 사용 가능한 네트워크 인터페이스 중에서 현재 사용 중이지 않고, 사용자 단말의 네트워크 인 터페이스가 접속할 수 있는 것을 우선적으로 할당한다. 이 후 로컬의 OVS와 단말의 OVS에 해당 인터페이스를 사용 할 수 있도록 플로우 테이블 수정 명령을 내린다. 수정 명령 은 단말의 OVS에서 자체적으로 지원되는 외부 관리용 $\mathrm{TCP}$ 인터페이스를 사용하며 ${ }^{[8]}$ 서버로부터 전달받은 사용 가능한 전송 계층 포트 번호를 각각의 인터페이스에 할당 하는 방식으로 이루어진다. 즉, 전송 계층 포트 번호로 플로 우를 구분하여 동시에 다수의 무선 접속 기술을 사용할 수 있도록 제어한다. 마지막으로 클라이언트에게 플로우 테이 블 수정 명령 시에 포함시켰던 전송 계층 포트 번호 목록을 포함한 응답을 전송한다. 이후 클라이언트는 그림 5 와 같은 절차로 서버에 이 전송 계층 포트 번호를 포함한 전송 요청 을 보냄으로써 트래픽을 주고받게 된다. 이 전송 요청을 받 은 비디오 콘텐츠 서버는 그림 3에서 MRAT(Multiple Radio Access Technology) 컨트롤러에게 전달해 준 TCP/ UDP 포트 번호와 동일한 개수만큼 전송할 비디오 파일을 나누어 각각의 포트 번호를 사용하여 클라이언트에게 전달 하게 된다. 한편, 그림 3 에서와 같이, 비디오 서비스가 구동 되고 있는 OpenStack 클라우드 플랫폼과, 액세스 네트워크 에 존재하는 OpenFlow 스위치 사이의 네트워크는 단일 유 선 이더넷 링크이며 $1 \mathrm{Gbps}$ 의 전송 대역폭을 갖는다. 따라 서 해당 단일 유선 링크를 사용하여 나누어진 비디오 파일 을 전송하게 된다. 그러나 OpenFlow 스위치와 사용자 단말 


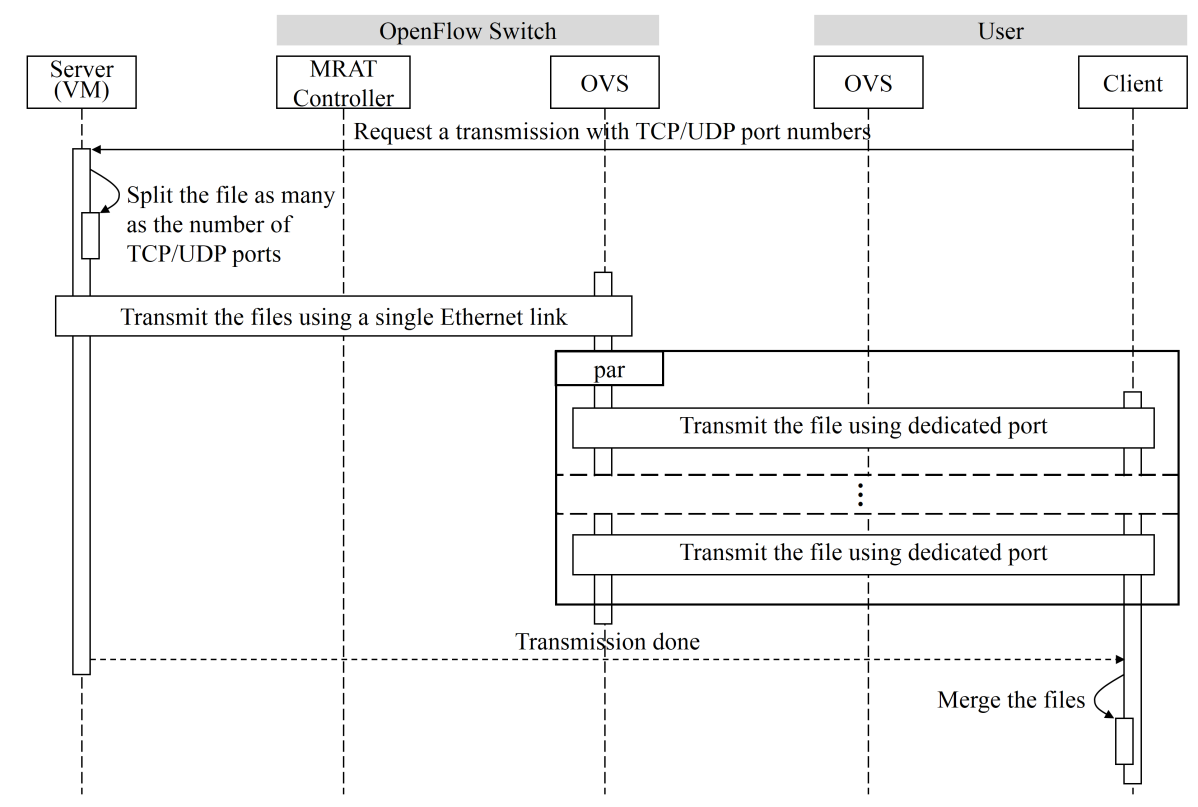

그림 5. 제안하는 다중 무선 접속 기술 제어를 통한 대용량 비디오 파일 전송

Fig. 5. Transmission procedure for large capacity of video file

사이에는 다수의 무선 랜 링크가 사용 가능하며, 각각의 무 선 링크에 대해 TCP/UDP 포트 번호로 플로우 테이블이 설 정되어 있다. 따라서 OpenFlow 스위치와 사용자 단말 사이 에서는 플로우 설정에 따라 비디오 파일들을 동시에 다수 의 링크를 사용하여 병렬 전송하게 된다. 이후 사용자 단말 의 클라이언트는 나누어져 수신한 파일을 하나로 합친 후 에 해당 파일을 사용할 수 있게 된다.

\section{IV. 성능 평가 및 분석}

본 논문에서 제안한 방안의 성능 평가를 위하여 OpenStack과 SDN 기술을 기반으로 테스트베드를 구축하였다. 본 장에서는 구축한 테스트베드의 구조를 설명하고, 성능 평가의 결과를 분석한다.

\section{OpenStack 및 SDN 기반의 테스트베드}

본 논문에서는 비디오 서비스 제공을 위해 소규모의
OpenStack 클라우드 플랫폼을 구축하고, 해당 클라우드 플 랫폼과 사용자의 단말 사이의 네트워크에 OpenFlow 스위 치가 존재하여 사용자와 목적지 서버 사이의 트래픽을 플 로우로 구분하고 관리하였다. 전체적인 테스트베드의 구성 도는 그림 6과 같다. 먼저, 모든 OpenStack 클라우드 노드 들은 X86 아키텍처 기반의 $\mathrm{PC}$ 로 구성되어 있으며 리눅스 우분투 12.04 버전 배포판 위에서 OpenStack Grizzly 버전 을 기반으로 구축되었다. 또한 실제 가상머신이 구동되는 컴퓨트 노드, 가상머신이 외부 네트워크에 접속할 수 있도 록 네트워크 관리를 수행하는 네트워크 노드, 그리고 전체 컴퓨트 노드 및 클라우드 관련 컴포넌트들을 관리하는 컨 트롤러 노드로 이루어진다. 이들 노드들은 내부 네트워크 를 이루며, 앞서 설명한 바와 같이 모든 가상 머신의 트래픽 은 네트워크 노드를 거쳐 외부로 나갈 수 있다.

네트워크 노드는 가상 머신이 외부에서 접근 가능한 공 인 IP 주소를 사용하도록, 내부에서 가상 머신이 사용하는 사설 IP 주소와의 NAT(Network Address Translation)를 수 행한다. 따라서, 사용자의 단말은 가상 머신의 공인 IP 주소 를 목적지로 하여 클라우드 비디오 서비스를 제공받는다. 


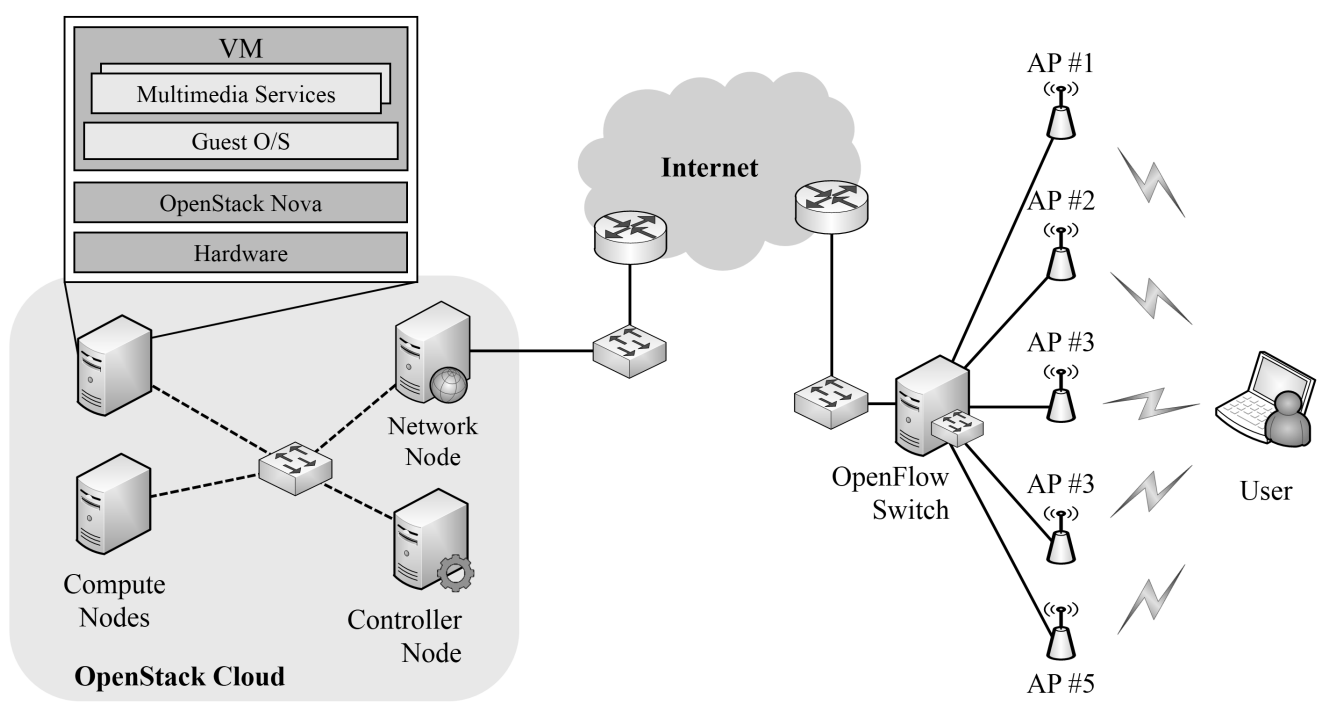

그림 6. 성능 평가를 위해 구축된 OpenStack 및 SDN 테스트베드 구성도

Fig. 6. The architecture of test-bed consist of OpenStack and SDN for performance evaluation purpose

또한, OVS가 설치된 x86 아키텍처 기반의 PC가 OpenFlow 스위치로 사용되었다. 해당 $\mathrm{PC}$ 는 다수의 네트워크 인 터페이스 카드를 장착하고 있으며, 리눅스 우분투 12.04 버 전 배포판이 설치되어 있다. 특히, 단말과 인접한 액세스 네트워크에 위치하는 OpenFlow 스위치의 경우 무선 랜 인 터페이스가 장착되어 있으며 사용자 공간 데몬으로 동작하 는 Hostapd ${ }^{[19]}$ 를 통해 각각의 무선 랜 인터페이스가 무선 액세스 포인트와 같이 동작하도록 하였다.

\section{2. 성능 평가 결과}

본 논문의 성능 평가는 그림 6에서와 같이, 실제 OpenStack 클라우드 플랫폼 및 OpenFlow 스위치, 그리고 Open vSwitch 기반의 다중 무선 접속 기술 제어가 지원되는 사용 자 단말을 사용하여 진행하였다. 따라서 비디오 서비스가 제공되는 컨텐츠 서버인 가상 머신에서 OpenStack 클라우 드 내부 네트워크를 거쳐 OpenFlow 스위치까지 연결되는 유선 링크는 $1 \mathrm{Gbps}$ 의 이더넷 링크이며, OpenFlow 스위치 는 Hostapd ${ }^{[19]}$ 를 이용하여 다섯 개의 무선 랜 인터페이스를 $\mathrm{AP}$ 모드로 동작시키며 $\operatorname{SSID}$ (Service Set Identifier)와 무선 링크 정보는 표 1 과 같다.
표 1. OpenFlow 스위치의 무선 랜 인터페이스 정보 Table 1. Information of WLAN interfaces of OpenFlow switch

\begin{tabular}{|c|c|c|c|}
\hline AP Name & SSID & Frequency (Ch.) & Note \\
\hline AP \#1 & osws_01 & $2.412 \mathrm{GHz}$ (Ch. 1) & HT20 \\
\hline AP \#2 & osws_02 & $2.452 \mathrm{GHz}$ (Ch. 9) & HT20 \\
\hline AP \#3 & osws_03 & $5.220 \mathrm{GHz}$ (Ch. 44) & HT40+ \\
\hline AP \#4 & osws_04 & $5.745 \mathrm{GHz}$ (Ch. 149) & HT40+ \\
\hline AP \#5 & osws_05 & $5.805 \mathrm{GHz}$ (Ch. 161) & HT40- \\
\hline
\end{tabular}

성능 평가는 IV장의 3 절에서 설명 된 플로우 제어 기법을 그대로 적용하되, 대역폭 측정 프로그램인 Iperf를 ${ }^{[20]}$ 사용 하여 진행하였다. 즉, 가상머신 위에서 다섯 개의 Iperf 서 버 프로세스를, 사용자 단말에서 역시 다섯 개의 Iperf 클라 이언트 프로세스를 각각 구동시킨 후 프로세스 마다 서로 다른 UDP 포트 번호를 이용하여 링크의 최대 대역폭을 측 정하였다. 이때, 다섯 개의 무선 랜 링크의 대역폭 합이 유 선 이더넷 링크의 $1 \mathrm{Gbps}$ 보다 작으므로 대역폭 측정이 이 루어진 구간에서 병목 현상은 발생하지 않았으며 안테나를 서로 떨어뜨려 놓아 무선 신호 간의 간섭으로 인한 대역폭 감소를 최소화하였다.

측정 결과는 그림 7 과 같았다. 두 개의 $2.4 \mathrm{GHz}$ 무선 링크 는 $20 \mathrm{MHz}$ 폭의 채널을 사용하고 두 개의 수신 및 송신 


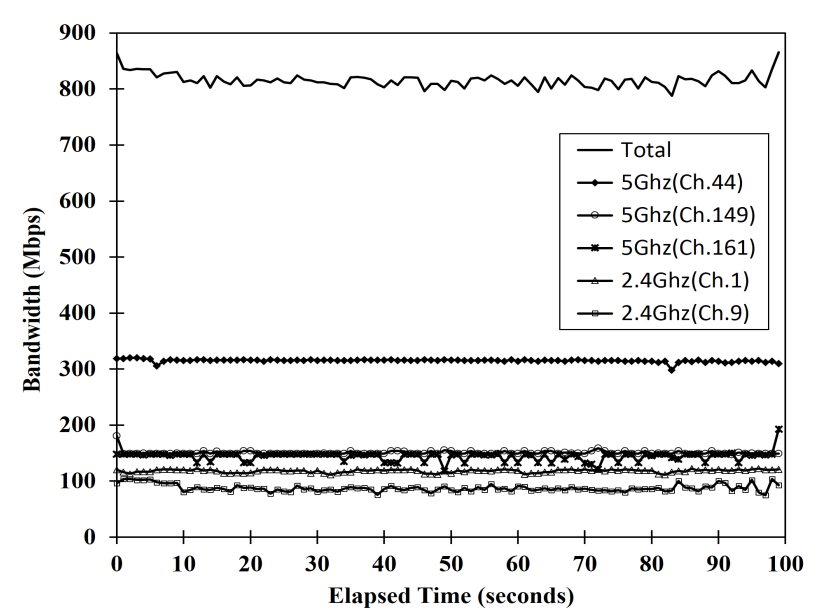

그림 7. 무선 링크 별 대역폭 측정 결과

Fig. 7. The result of bandwidth measurement per wireless link

스트림을 사용하였으므로 각각 약 $100 \mathrm{Mbps}$ 의 최대 대역폭 이 측정되었다. 나머지 세 개의 $5 \mathrm{GHz}$ 무선 링크는 모두 $40 \mathrm{MHz}$ 폭의 채널을 사용하고 세 개의 수신 및 송신 스트림 을 사용하였으나, 149 번 채널과 161 번 채널 링크의 경우 상호 간섭이 일어나 대역폭이 다소 줄어들었다. 44번 채널 링크의 경우에는 약 $310 \mathrm{Mbps}$ 의 최대 대역폭이 측정되었 고, 다섯 개의 무선 링크를 통해 $820 \mathrm{Mbps}$ 의 전송 대역폭을 확보할 수 있었다.

\section{V. 결 론}

본 논문에서는 $\mathrm{SDN}$ 기술을 기반으로 하는 다중 무선 접 속 기술 제어 기법을 제안하였다. 실제 성능 평가에서는 OpenStack 기반의 클라우드 플랫폼 위에서 비디오 콘텐츠 를 제공하는 것이 고려되었고, 무선 접속 기술로는 각각 다 른 채널의 무선 랜이 고려되었다. 또한 실제 다섯 개의 무선 랜 링크를 동시에 사용하여 약 $820 \mathrm{Mbps}$ 의 전송 대역폭을 확보할 수 있었다.

다만 본 논문의 제 $\mathrm{I}$ 장에서 수행한 성능 평가는, 각 무선 링크의 상태가 주변 요인의 영향을 받지 않는 최대한 안정 적인 상황에서 진행되었다. 이는 서로 다른 주파수 대역의 이종 무선 랜 채널을 동시에 사용하였을 때 가용한 최대
전송 대역폭을 측정하기 위함이나, 일반적으로 다양한 외 부 변인으로 인해 무선 링크가 안정적이지 않은 경우가 많다. 따라서 향후 연구에서는 동적으로 무선 링크의 상 태를 주기적으로 모니터링 하여 이를 바탕으로 사용할 무 선 링크를 결정하는 기능이 추가됨으로써 보다 현실적인 연구 결과를 낼 수 있을 것으로 보인다. 또한, 무선 링크의 상태가 매우 가변적인 경우에도 본 연구에서 제안한 데이 터 전송 기법을 사용함으로써 상태가 좋은 무선 링크로 보다 많은 파일을 전송하고, 상대적으로 상태가 좋지 않 은 무선 링크로는 그보다 작은 개수의 파일을 전송하게 되어 결과적으로 사용자 입장에서는 서로 다른 무선 링크 의 가용한 무선 자원을 최대한 활용하여 서비스를 제공받 을 수 있다.

나아가 현재 기가비트급 전송 속도를 목표로 표준화 중 인 IEEE $802.11 \mathrm{ac}^{[21]}$ 가 $5 \mathrm{GHz}$ 의 주파수 특성상 전송거리 및 장애물에 제약이 있는 단점을 고려하여, 경우에 따라 $2.4 \mathrm{GHz}$ 기반의 무선 랜 인터페이스들을 사용함으로써 보 다 먼 거리 또는 장애물이 있는 실내 상황에서 기가비트에 근접한 전송 속도를 구현하는 방안도 고려할 수 있다. 아울 러 $5 \mathrm{GHz}$ 를 지원하는 IEEE $802.11 \mathrm{n}$ 과 $802.11 \mathrm{ac}$ 의 무선 랜 인터페이스를 복수개 사용하여 기가비트급 이상의 속도를 제공함으로서 무 압축 비디오 서비스의 실현도 가능해질 수 있다.

\section{참 고 문 헌 (References)}

[1] Cisco White Paper, Cisco Visual Networking Index: Forecast and Methodology, 2012-2017, May 2013.

[2] Ericsson, Ericsson Mobility Report, accessed Jan. 15, http://www. ericsson.com/res/docs/2013/ericsson-mobility-report-june-2013.pdf.

[3] Demestichas, P., Georgakopoulos, A., Karvounas, D., Tsagkaris, K., Stavroulaki, V., Lu, J., Xiong, C., and Yao, J., 5G on the Horizon: Key Challenges for the Radio-Access Network, IEEE Vehicular Technology Magazine, 8(3), pp.47-53, Sep. 2013.

[4] Gustafsson, E., and Jonsson, A., Always best connected, IEEE Wireless Communications, 10(1), pp.49-55, Feb. 2003.

[5] Kellokoski, J., Koskinen, J., Nyrhinen, R., and Hamalainen, T., Efficient Handovers for Machine-to-Machine Communications Between IEEE 802.11 and 3GPP Evolved Packed Core Networks, Green Computing and Communications (GreenCom) 2012. IEEE International Conference on, pp.722-725, Nov. 2012. 
[6] Kellokoski, J., Koskinen, J., and Hamalainen, T., Context and location aware always-best-connected concept for heterogeneous network, Wireless Days (WD). 2012 IFIP, pp. 1-3, Nov. 2012.

[7] McKeown, N., Anderson, T., Balakrishnan, H., Parulkar, G., Peterson, L., Rexford, J., Shenker S., and Turner, J., OpenFlow: enabling innovation in campus networks, ACM SIGCOMM Computer Communication Review, 38(2), pp.69-74, Apr. 2008.

[8] Pfaff, B., Pettit, J., Amidon, K., Casado, M., Koponen, T., and Shenker, S., Extending Networking into the Virtualization Layer, Hotnets, Oct. 2009.

[9] OpenStack official web site, accessed Jan. 15, http://www.openstack. org/.

[10] Kim D., Yi G., and Lee S., A Study on the Multiple Network Interfaces Control using Open vSwitch and OpenFlow, Korea Computer Congress 2011 (KCC 2012), 40(1), pp.921-923, Jun. 2013.

[11] Ford, A., Raiciu, C., Handley, M., Barre, S., and Iyengar, J., Architectural guidelines for multipath TCP development, RFC 6182, Mar. 2011.

[12] Stewart, R., Stream control transmission protocol, RFC 4906, Jun. 2007.

[13] Casado, M., Freedman, M. J., Pettit, J., Luo, J., McKeown, N., and Shenker, S., Ethane: Taking control of the enterprise. ACM SIGCOMM Computer Communication Review, 37(4), pp.1-12, Aug. 2007.
[14] Yoon, B., Lee, B., and Pitt, D., Future Networking Technology of SDN, Electronics and Telecommunications Trends, 27(2), 2012.

[15] Gude, N., Koponen, T., Pettit, J., Pfaff, B., Casado, M., McKeown, N., and Shenker, S. NOX: towards an operating system for networks, ACM SIGCOMM Computer Communication Review, 38(3), pp.105-110, Jul. 2008.

[16] Floodlight project official web site, accessed Jan. 15, http://www. floodlightproject.org/floodlight/.

[17] Open Networking Foundation, OpenFlow Switch Specification, accessed Jan. 15, https://www.opennetworking.org/images/stories/downloads/sdn-resources/ onf-specifications/openflow/openflow- spec-v1.2. pdf.

[18] Astely, D., Dahlman, E., Fodor, G., Parkvall, S., and Sachs, J., LTE release 12 and beyond, IEEE Communications Magazine, 51(7), pp.154-160, Jul. 2013.

[19] Hostapd official web site, accessed Jan. 15, http://hostap.epitest.fi/hos$\operatorname{tapd} /$.

[20] Iperf official web site, Iperf: The TCP/UDP bandwidth measurement tool, accessed Jan. 15, http://iperf.fr/.

[21] Ong, E. H., Kneckt, J., Alanen, O., Chang, Z., Huovinen, T., and Nihtila, T., IEEE 802.11 ac: Enhancements for very high throughput WLANs. Personal Indoor and Mobile Radio Communications (PIMRC). 2011 IEEE 22nd International Symposium on, pp.849-853, Sep. 2011.

\section{저 자 소 개}

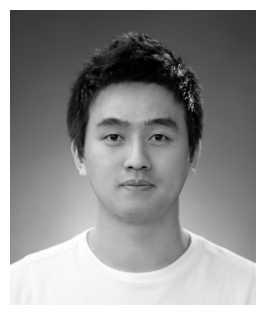

\section{김 동 하}

- 2012년 : 경희대학교 컴퓨터공학과 학사

- 2012년 현재 : 경희대학교 컴퓨터공학과 석사과정

- 주관심분야 : 클라우드 컴퓨팅, 소프트웨어 정의 네트워크, 무선 통신

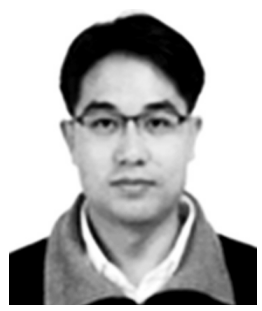

\section{이 성 원}

- 1994년 : 경희대학교 전자계산공학과 학사

- 1996년 : 경희대학교 전자계산공학과 석사

- 1998년 : 경희대학교 전자계산공학과 정보통신전공 박사

- 1999년 2008년 : 삼성전자 정보통신총괄 책임연구원

- 2008년 현재 : 경희대학교 컴퓨터공학과 부교수

- 주관심분야 : 이동통신 시스템, 이동통신 서비스, MAC 프로토콜 